\title{
Assessment and prediction of water resources based on Grey Theory
}

\section{Hongwang Yang}

Department of electrical engineering , North China Electric Power University, Baoding 071000,
China

956598589@qq.com

Keywords: $\operatorname{GM}(1,1)$, water scarcity,water demand and supply index.

\begin{abstract}
The ability of a region to provide clean water relates to many aspects of the physical and economic elements. We use natural and social indicators to evaluate this feature.

To measure the ability of a region to provide clean water to meet the needs of its population, water demand and supply index (WDSI) is defined as the ratio of the amount of water demand and water supply. Obviously, if the index $>1$, the region is suffering from water scarcity. Water demand includes industrial water, agricultural water and domestic water. Water supply consists of surface water, groundwater and other clean water. To evaluate this model, we select six countries spreading in five Water stress indicator interval in the UN water scarcity map and calculate their WSDI from 1988 to 2002. Then we apply the cluster analysis to divide the countries into five classes. The test result fits water stress indicator interval showed by the UN water scarcity map perfectly.

We choose Beijing for our further investigation where water is heavily overloaded. Considering the dynamic nature of the factors, we adopt the supply and demand balance theory and GM $(1,1)$ to predict the development trend of water supply and demand separately. According to the forecast, water shortage in Beijing will be more serious in the next 15 years. Industrial water will increase gradually. Sewage reuse, rainwater harvesting project and water desalination projects will make great progress, which will provide a large proportion of the water supply in the future.
\end{abstract}

\section{Introduction}

During the last twenty years, researchers have developed a number of metrics to help characterize, map and track the geography of water scarcity globally. These have included, for example, the ratio of population size to the renewable water supply [1] and the ratio of water withdrawals to the renewable supply [2]. These water scarcity indicators have highlighted the mismatch between water availability and water demand, and have helped document the spread of water scarcity over time. Today, water scarcity assessments underpin global assessments of food, poverty and human development, economic and business prospects and ecological health. Given this widespread use of water scarcity indicators, their accuracy is at a premium.

\section{Symbols and Definitions}

\begin{tabular}{|c|c|c|c|}
\hline Symbols & Definitions & Symbols & Definitions \\
\hline$A W$ & Water supply & $Q_{t 0}$ & $\begin{array}{l}\text { Industrial water consumption } \\
\text { in the beginning }\end{array}$ \\
\hline$D E M$ & Water demand & Sw & Surface water \\
\hline$W S$ & Lift-to-drag ratio for missing aircraft & $G w$ & Groundwater \\
\hline$\Delta W$ & Water shortage & $D w$ & Desalination water \\
\hline \multirow[t]{2}{*}{$Q_{t}$} & total industrial water consumption & $\mathrm{Sr}$ & Sewage reuse \\
\hline & Domestic water & $Q_{t i}$ & $\begin{array}{l}\text { Industrial water demand } \\
\text { forecast for one year }\end{array}$ \\
\hline
\end{tabular}




\section{Assumptions And Justifications}

The accuracy of our models rely on certain key, simplifying assumptions. These assumptions are listed below:

- The yield of water provided from desalinization plants and water harvesting techniques will increase according to certain rules. We suppose that it is reasonable to forecast their production by analyzing data from previous years using some methods like grey prediction model.

- The industrial, agricultural and domestic water demands are increasing or decreasing exponentially. For domestic water demands, we assume per capita domestic water consumption is constant so that total domestic water consumption is proportional to population.

- The amount of precipitation in Beijing will wave according to the regulation showed by data from previous years. We assume that it is reasonable to forecast annual precipitation by means of researching data from previous years.

- The statistical data is accurate. We suppose the data collected from website is reliable.

- The region we choose will develop steadily. Terrible disasters such as plague and war won't take place in Beijing therefore the population, agriculture and industry won't suffer external influence.

\section{Supply and demand balance Model}

Water supply and demand balance analysis, which refers to analyzing the relationship between supply and demand in a certain area for water quantity and water requirement of different periods.

$$
A W-D E M=\Delta W
$$

If $\Delta W>0$, it indicates that the region can provide clean water to meet the needs of its population.

If $\Delta W<0$, the result indicates that the region is suffer from water scarcity

If $\Delta W=0$, the result indicates that the region reach the water supply and demand balance

A study by Zhen Wang on regional carrying capacity of water resources describes the relation between regional socio-economic population and the carrying capacity of regional water resources, but it does not take into account the natural supply and demand of resources and social economy. For this, We define (WSDI).

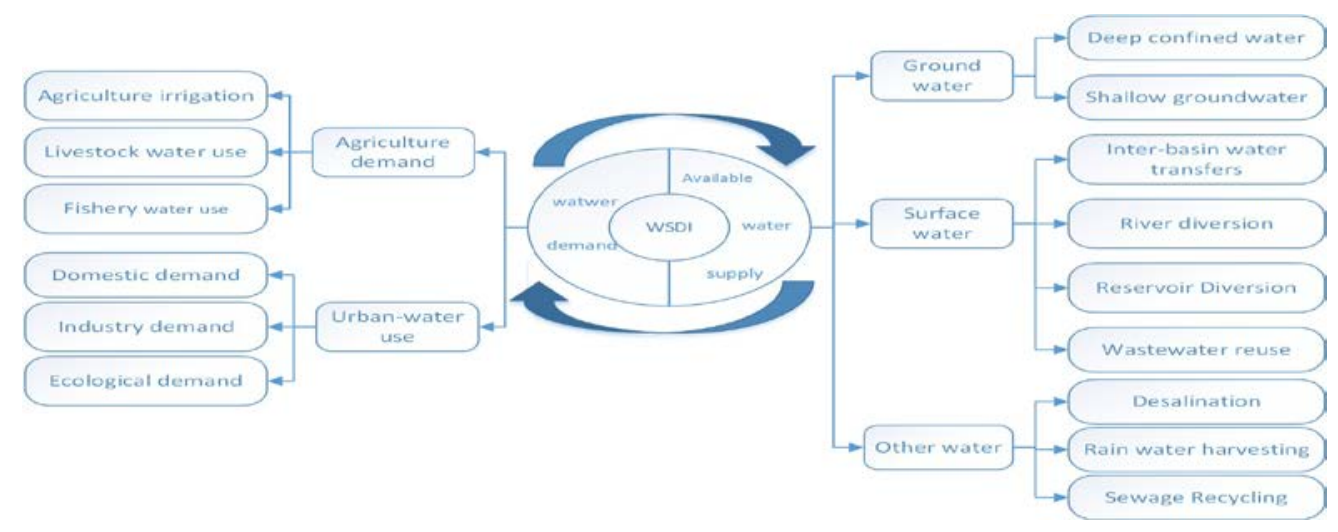

Figure 1 Water supply and demand index

Water supply and demand index consists of two parts: The first part is the water supply model, the second part region water demand model.

\section{1 the supply model}

Available water consists of surface water, groundwater, inter-basin water transfer, sewage reuse desalination.The calculation method of the available water is as follows:

$$
A W=S w+G w+I w t+S r+D w
$$


Where $A W$ represents available water. $S w$ represents surface water.

$G w$ represents groundwater. Iwt represents Inter-Basin Water Transfer,

$\mathrm{Sr}$ represents sewage reuse. $\mathrm{Dw}$ represents Desalination water

\subsection{The Demand Model}

Water demand analysis is one of the main elements of supply and demand balance, which is made up of industrial water, agricultural water, domestic water, etc

Since the industrial water in different industries vary widely, it can be calculated as follows:

$$
Q_{t}=Q_{C}+Q_{d}+Q_{r}
$$

Where $Q_{t}$-total industrial water consumption $\mathrm{m}^{3} / a, \quad Q_{c}$-industrial water consumption, $\mathrm{m}^{3} / a$ $Q_{r}$-industrial repeat water consumption, $\mathrm{m}^{3} / \mathrm{a}$

We use the industrial water consumption growth rate over the years to calculate the industrial water consumption in the future.

$$
Q_{t i}=Q_{t 0}(1+d)^{n}
$$

$Q_{t i}$ - Industrial water demand forecast for one year, m3

$Q_{t 0}$ - Industrial water consumption in the beginning , m3;

$d$-Annual average growth rate of industrial water consumption, $\%$;

$n$-The time interval from the start of the year to the year that is predicted , a

We use the per capita living water quota method to calculate the domestic water, it is calculated as:

$$
Q_{\text {life }}=\frac{365 q m}{1000}
$$

Where $Q_{\text {life }}$ represents Domestic water, $m 3$ / a, q represents Per capita water quota ,L / ( per $\bullet$ d)

$m$ represents Population that consume water in the forecast period, per

The annual population can be predicted based on population growth rate.Compared with the urban industrial and domestic water,agricultural water mainly includes agricultural irrigation, water required by livestock, fishery water and township enterprises water.

$$
Q_{a g r}=Q_{A i}+Q_{L w u}+Q_{F w u}
$$

Where $Q_{A i}$ represents agricultural irrigation . $Q_{L w u}$ represents water required by livestock.

$Q_{F w u}$ represents fishery water .

Water demand is calculated as follows: $\quad D E M=Q_{t}+Q_{\text {life }}+Q_{a g r}$

\subsection{The Water Supply and Demand Index}

We build a water exponential model to describe the relationship between supply and demand in an area, which has a direct or indirect contact with its socio-economic and natural conditions in the area.The water supply model takes into account the per capita water availability and the water content of the various region .Water demand model takes into account the domestic water, industrial water, agricultural water, ecological water. WSDI can be calculated as follows:

$$
W D S I=\frac{D E M}{A W}
$$

Where $A W$ represents The amount of available water resources, $D E M$ represents Water demand

\subsection{Tests for WSDI}

To evaluate the accuracy of the model, we take six countries from the UN water scarcity map as an example .These countries are Australia, Algeria, Egypt, Germany, Libya and Turkey .Their water stress indicators are as follows:

Table 1 The level of water scarcity

\begin{tabular}{llllll}
\hline Australia & Germany & Turkey & Algeria & Egypt & Libya \\
\hline No water stress & Slightly & Slightly & Moderately & Heavily & over-exploited \\
\hline
\end{tabular}

We collect water resources data of these countries from 1993 to 2002. Since there are a few missing data, we take data every 5 years. For each country, we get its water demand ( $D E M$ ) and total 
available water ( $A W$ ). Then we calculate Water supply and demand index (WSDI ) which is presented in the following Table.

Table 2 The WSDI of country

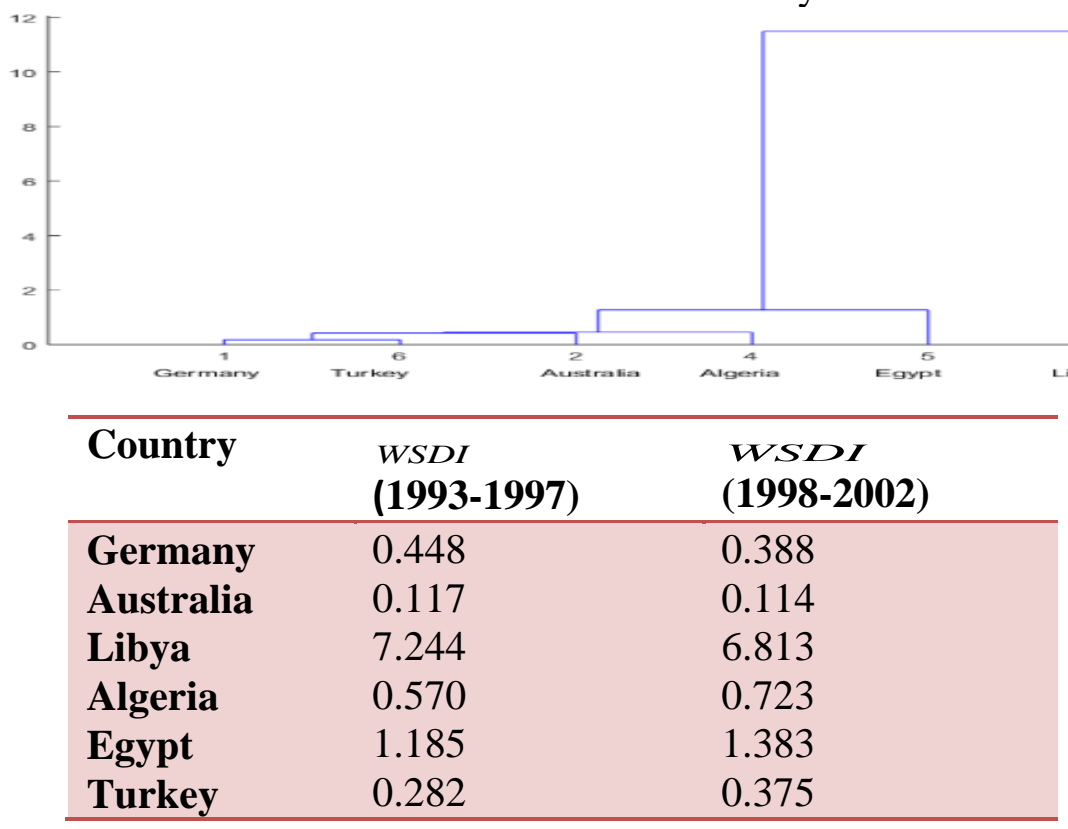

Figure 2 Clustering

When $0<W D S I<1$, it indicates that the area of adequate water supply, no water shortage, and the smaller the value, the stronger the ability of water supply.If $W S D I>1$, it indicates that the water supply in the region is weak, and the larger the value, the more serious water shortages.

To evaluate the model, we apply clustering method to divide the countries into 5 classes using these data and compare the results with water stress indicators provided by the UN water scarcity map. The result is shown in Table 2 and Figure2. We can find that Water supply and demand index (WSDI) of Libya in the past 10 years is much higher than other countries, so Libya can be divided into a class which stands for severe stress for water. Moreover, Germany and Turkey have the similar index during the past 10 years, we divide them into one class standing for slight stress for water resource. Through analyzing the classification, we can draw a conclusion that our model is general and effective.

\subsection{Water Supply Prediction}

In order to forecast the development trend of global and local water supply, we not only consider the forecast of total supply situation, but also the water supply situation in each subsystem,

First, with the theory of GM $(1,1)$, we predict the total water supply in the next 15 years without consider the subsystems.Second, we forecast the amount of surface water, groundwater, other water in the next 15 years, and then we plus together three water supply for the total water supply. 
Table 3 The Prediction of supply water

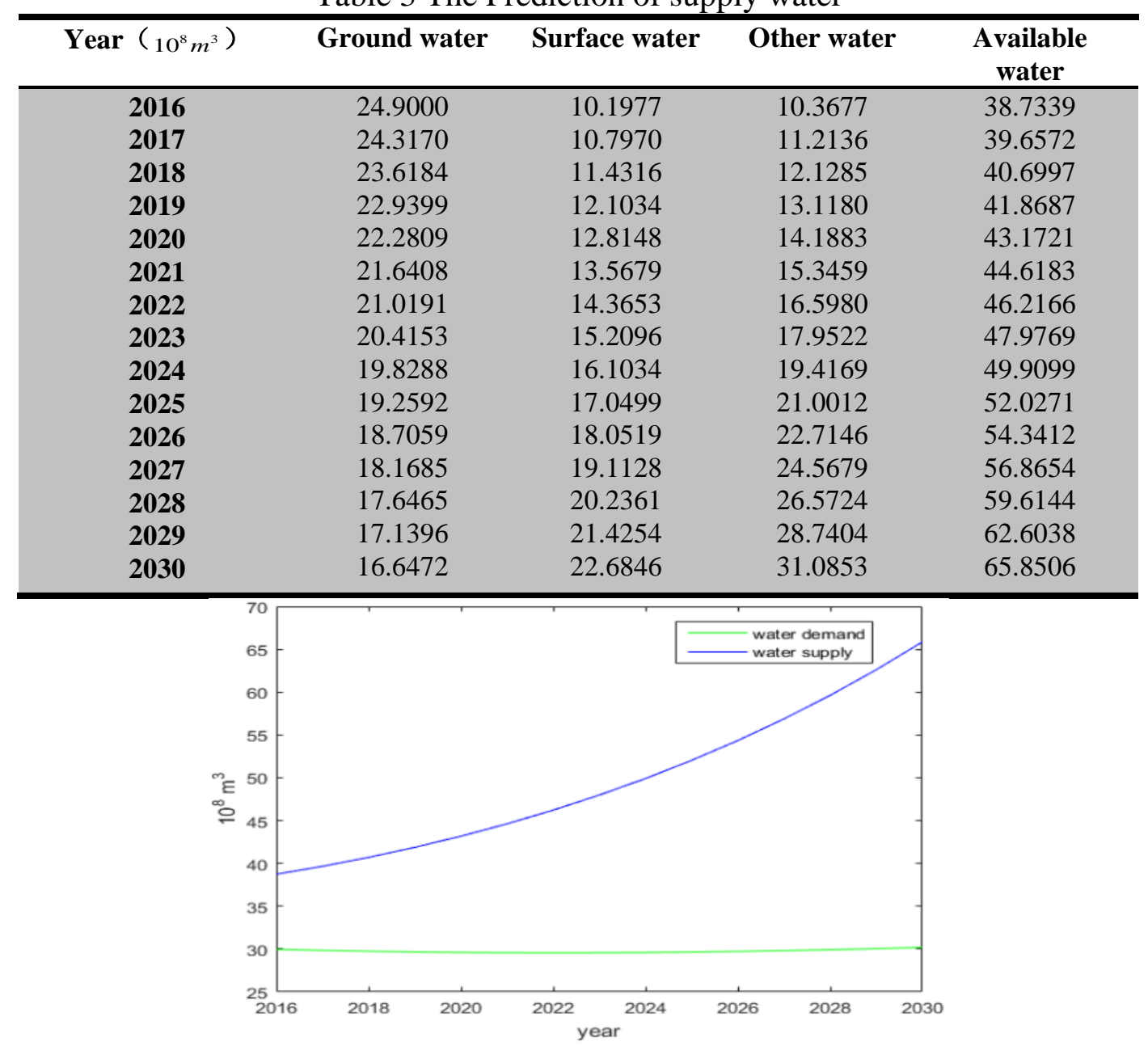

Figure3 The prediction of water demand and water supply

\section{Summary}

The next 15 years, the amount of water in other water sources such as sewage treatment and reuse, rainwater harvesting project and desalination projects have made great progress. It makes total water supply has been a slow improvement in reducing groundwater scarcity .Therefore, it reduce the groundwater supply pressure, so that water can become cleaner and be efficiently recycled. However, due to the increased water demand, especially industrial water, In 15 years, water demand has doubled. If measures are not taken, water pollution will be more severe, exacerbating the conflict between water supply and demand. Besides, Sewage reuse, rainwater harvesting project, water desalination projects as the potential for new or alternate sources of water, will account for a large proportion of the water supply in the future. Moreover, the population will be an important factor restricting water, what's more, not only the environment is limited to water supply, but also the social factors affect the availability and distribution of clean water.

\section{References}

[1] Falkenmark M. The massive water scarcity now threatening Africa: why isn't it being addressed?[J]. Ambio, 1989: 112-118.

[2] Oki T, Kanae S. Global hydrological cycles and world water resources[J]. science, 2006, 313(5790): 1068-1072.

[3] [6] Seckler D W. World water demand and supply, 1990 to 2025: Scenarios and issues [M], 1998. 
[4] Yu M, Wu S P. Influence of the Heating Conditions on the Asphalt Compositions by Grey System Theory[C]//Advanced Materials Research. 2011, 306: 1673-1677.

[5] National Bureau of Statistic of China http://data.stats.gov.cn/index.htm

[6] AQUASTAT http://www.fao.org/nr/water/aquastat/water_res/index.stm) 